\title{
Is there an urban-rural-gradient in patients with urinary incontinence?
}

\author{
Sebastian Wille, MD; Kawa Katarzyna, MD; Ulrike Ahrens, MD; Okyaz Eminaga, MD; Udo Engelmann, MD; \\ Paas Jenny, MD
}

Department of Urology, University Hospital of Cologne, Kerpener Straße. Cologne, Germany

Cite as: Can Urol Assoc J 2014;8(3-4):e126-31. http://dx.doi.org/10.5489/cuaj.1488 Published online March 11, 2014.

\section{Abstract}

Introduction: The objective of this study was to determine whether the responses to the same questionnaire differ between women living in a large city and women living in a rural area.

Methods: We evaluated the medical records of 88 patients living in the large city of Cologne and of 86 patients living in Brühl and its surrounding rural regions. The responses on the International Consultation on Incontinence Questionnaire-Short Form (ICIQ-SF) of 88 patients who suffer from urinary incontinence and live in a large city were compared to the responses 86 patients who live the rural region of Brühl. In addition, ages, frequency of micturition, use of pads, prior and desired treatment were compared. Limitations of this study include its retrospective study design and the absence of sociodemographic data. Furthermore, the use of a pad test could objectify the extent of incontinence.

Results: On average, patients from Cologne used of 6.2 pads and patients from Brühl used 3 pads. Patients from the large city scored 14 out of 21 points on the ICIQ-SF, and women from Brühl scored 11 out of 21 points. This difference was significant. Patients from Cologne had received medicinal treatment or physical therapy significantly more often.

Conclusion: The results suggest that urinary incontinence is perceived as a greater impairment by patients residing in (large) cities compared to patients residing in rural areas. An urban-rural gradient in patients with urinary incontinence can be described.

\section{Introduction}

Urinary incontinence is a worldwide problem, and affects $8.2 \%$ of the population. ${ }^{1}$ Epidemiological data about urinary incontinence within the German population were published in 2005. As a part of this data collection, Beutel and colleagues have calculated a frequency of urinary incontinence within the general German population of $12.6 \%$, with a $15 \%$ frequency among the female population. ${ }^{2}$ Urinary incontinence strongly affects patient well-being and quality of life. ${ }^{3}$ It is known that incontinent patients' evaluation of their quality of life is subjective and depends on various factors. There are only a few studies that suggest a co-existence of incontinence and certain personality traits. ${ }^{2,4}$ Berglund and colleagues described a significantly higher proportion of patients who exhibit feelings of anxiety, neurotic tendencies, and psychological frailty if they continue to be incontinent after urinary incontinence surgery compared to patients who are continent after surgery. ${ }^{4}$ Even fewer publications deal with the question of whether there is an urban-rural gradient regarding urinary incontinence.

This study design was based on the therapist's subjective impression that there is a discrepancy between the claims of patients at the incontinence clinic in Cologne, a city with about 1 million residents, and the accounts of patients in Brühl (and surrounding regions), a city with about 44000 residents. It appeared that the patients at the Cologne clinic often made more dramatizing statements. This was the reason for the collection of objective data that take the living environment and housing situation into account.

\section{Methods}

All female patients 18 or older suffering from urinary incontinence (stress incontinence, urge incontinence or mixed incontinence) at 2 different incontinence clinics were included. We excluded female patients younger than 18 and male patients. One of the incontinence clinics was held at the Urological Clinic at the University Clinic Cologne and recruited patients from the large city of Cologne. The other clinic was held at the same time in Brühl, and patients from Brühl and its rural surroundings were treated here. Both clinics were held by the same urologist. Urban patients were seen at the Urological Clinic at the University Clinic Cologne and rural patients were seen at the Clinic in Brühl. We can confirm this because of the big distance between both clinics and because we checked the addresses from the patients at each clinic. The study population included 88 patients from Cologne and 86 patients from Brühl and its 
rural surroundings. The survey period was from September 2010 to August 2011.

We evaluated patient age, type of incontinence (stress incontinence, urge incontinence or mixed incontinence), frequency of micturition, number of pads used, prior and desired treatment. The distinction between the types of incontinence was based on the guidelines of the European Association of Urology (EAU) on Incontinence and the International Continence Society (ICS). ${ }^{5,6}$ In addition, we used the validated ICIQ-SF (International Consultation on Incontinence Questionnaire-Short form), which received a class A rating in the current Association of the Scientific Medical Societies' guidelines. ${ }^{7}$ The original version of this questionnaire consists of 4 questions. The total number of points from questions 1 to 3 is 21 points. Question 3 specifically addresses the impairment resulting from the involuntary loss of urine. The purpose of question 4 is to distinguish between the types of urinary incontinence. A validated German version of the ICIQ-SF was used. A question about the daily and nightly use of pads was added. Only the number of pads used was requested and there was no distinction about the absorbency of the pad. A pad test was not performed.

After consulting with the Ethics Commission, we determined that no vote was necessary because this was a retrospective study. The study was conducted in accordance with the ICH-GCP (International Conference on Harmonization of technical requirements for registration of pharmaceuticals for human use-Good Clinical Practice) guidelines.

Statistical analysis was performed with SPSS Statistics Version 19.0. Since there were 2 independent random samples from a population with non-normal distribution, we used the non-parametric Mann-Whitney $U$ Test (Wilcoxon test) to analyze the data.

\section{Results}

Aside from the information contained in the medical records, the answers on the validated questionnaire (ICIQ-SF) formed the basis of the analysis. Four questionnaires from the Brühl group and 3 from the Cologne group could not be evaluated; in total, we included 88 patients from Cologne and 86 from Brühl.

At the time of the consultation, the median age in the rural population was slightly higher, with 64.8 in the rural group compared to 63.2 years in the urban group. Both groups included mostly postmenopausal women. At the time of data collection, over $60 \%$ of the patients were over 60 (Fig. 1).

The median frequency of micturition in patients from Cologne was 10.7 in 24 hours, whereas in patients from Brühl and surrounding areas, the value was only 7.7. This difference was statistically significant $(p=0.001)$.

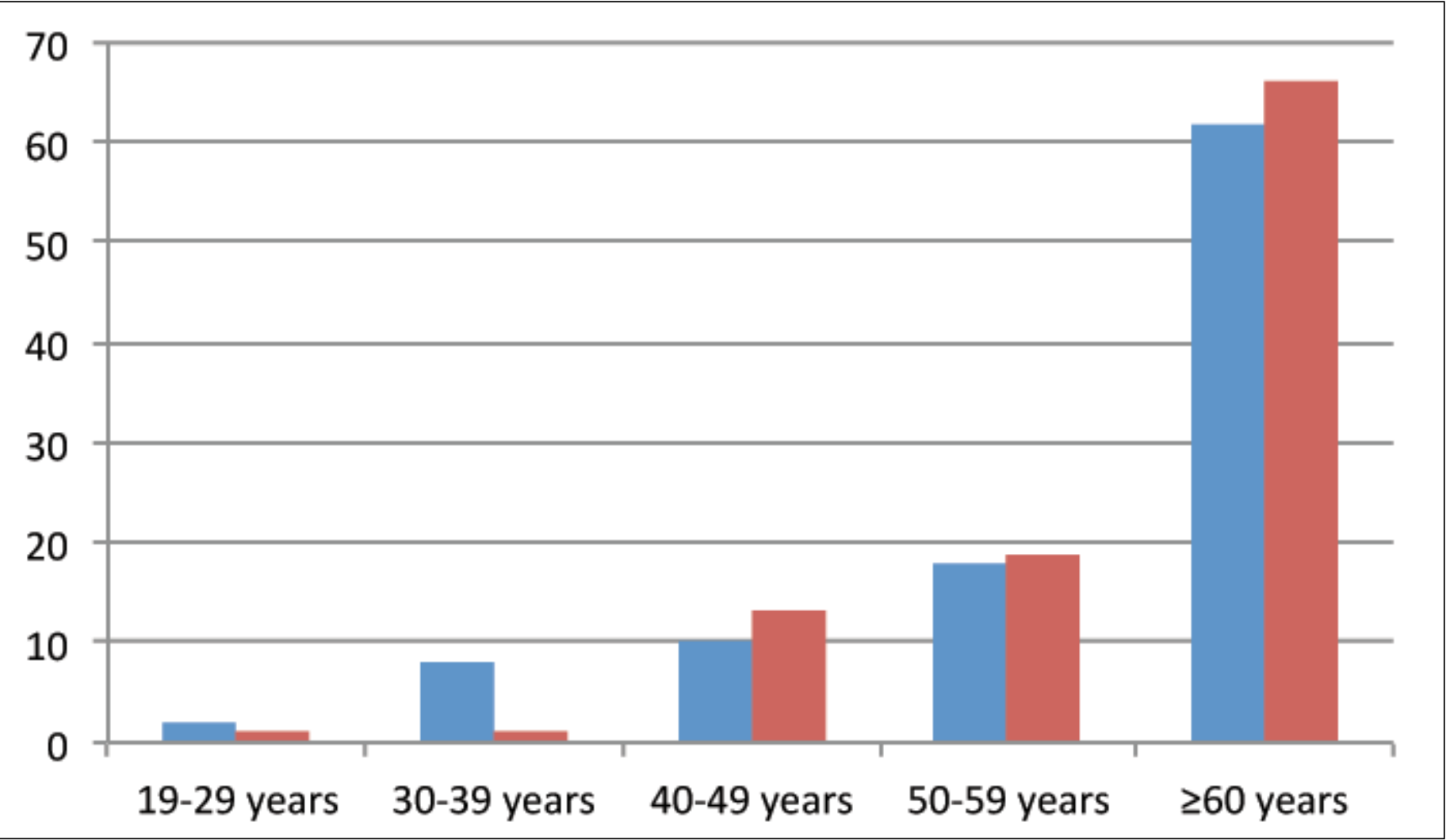

Fig. 1. Study population by age. Number in percentage. 
Wille et al.

Question 4 of the ICIQ-SF addresses the type of urinary incontinence. The proportion of stress incontinence, urge incontinence and mixed incontinence was similar in both study populations. In Cologne, $47 \%$ suffered from stress incontinence, $25 \%$ from urge incontinence and $28 \%$ from mixed incontinence. Among patients from rural areas, $42 \%$ suffered from stress incontinence, $22 \%$ from urge incontinence and $36 \%$ from mixed incontinence (Fig. 2).

The analysis of questions 1 to 3 on the ICIQ-SF revealed that patients from urban areas were significantly more likely to give answers that indicate a severe degree of incontinence. From the urban centre, $67 \%$ of patients indicated that they lose urine all the time or more than once a day (ICIQ-SF Question 1). In contrast, only $47 \%$ of the patients from Brühl gave this answer. At the same time, $8 \%$ of the patients from Cologne compared to $21 \%$ of the patients from Brühl indicated that they never experience an involuntary loss of urine (Fig. 3). With regard to the amount of urine lost, a similar distribution of responses was found (ICIQSF Question 2). Significantly more patients from Cologne indicated that they lost urine "very much," whereas more patients from Brühl indicated that they lot "none" (Fig. 4).

Half the patients (50\%) from Cologne group experienced severe impairment (ranking 8-10 out of 10 points) in their daily lives due to their urinary incontinence. From the Brühl group, only $32 \%$ of patients indicated this degree of severity (ICIQ-SF Question 3). Patients from rural areas were significantly more likely to state that the symptoms of urinary incontinence were causing "rather no impairment of everyday life" (25\% of rural patients vs. $10 \%$ of urban patients; ranking 0 to 1 out of 10 points) (Fig. 5).

At the time of data collection, $77 \%$ of patients from Cologne had been previously treated and every fifth patient from Cologne had undergone surgical treatment; in contrast, $48 \%$ of patients from Brühl had not been treated at all.
Patients from Cologne more frequently expressed a desire for a definitive solution to the problem, either surgical or medicinal. Surprisingly, 34\% of the patients from Brühl did not express a desire for treatment. The analysis also revealed that patients from urban areas used 6.2 pads on average per day, whereas patients from Brühl used an average of 3 pads per day.

The correlation of the number of pads used per day with the ICIQ-SF scores of both populations shows a significant difference between patients who did not use pads. A tendential difference in the ICIQ score of 17 in women from Cologne versus 15 in women from Brühl could be determined in patients who used more than 5 pads per day.

\section{Discussion}

It could be demonstrated that the group of patients from Cologne scored higher in every category with respect to severity of urinary incontinence, impairment resulting from their urinary incontinence and the desire for adequate medical treatment.

Based on these results, two different conclusions could be drawn. First, it is possible that although the severity of urinary incontinence may be similar, women from Cologne experienced greater psychological strain. Second, patients from Cologne could, on average, be suffering from more severe urinary incontinence, which could have contributed to the higher scores.

To determine the severity of urinary incontinence, information about the number of pads used per day was requested. The correlation of the ICIQ-SF sum score with the number of pads used per day revealed a significant difference between the groups, although the number of pads used per day was the same and, therefore, the degree of incontinence was presumably the same (no pads $p<0.05$ ) (Fig. 6). This

\section{Cologne}

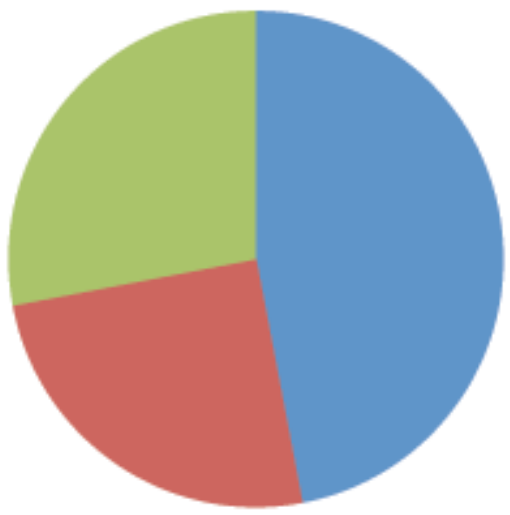

\section{Brühl}

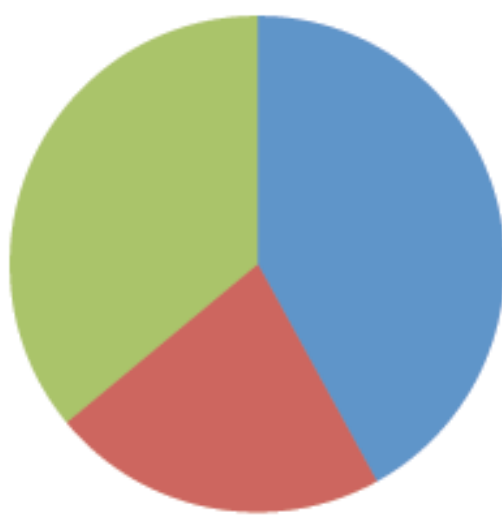

- Stress incontinence

Urge incontinence

Mixed incontinence

Fig. 2. Study population: percentage distribution of the types of incontinence. 


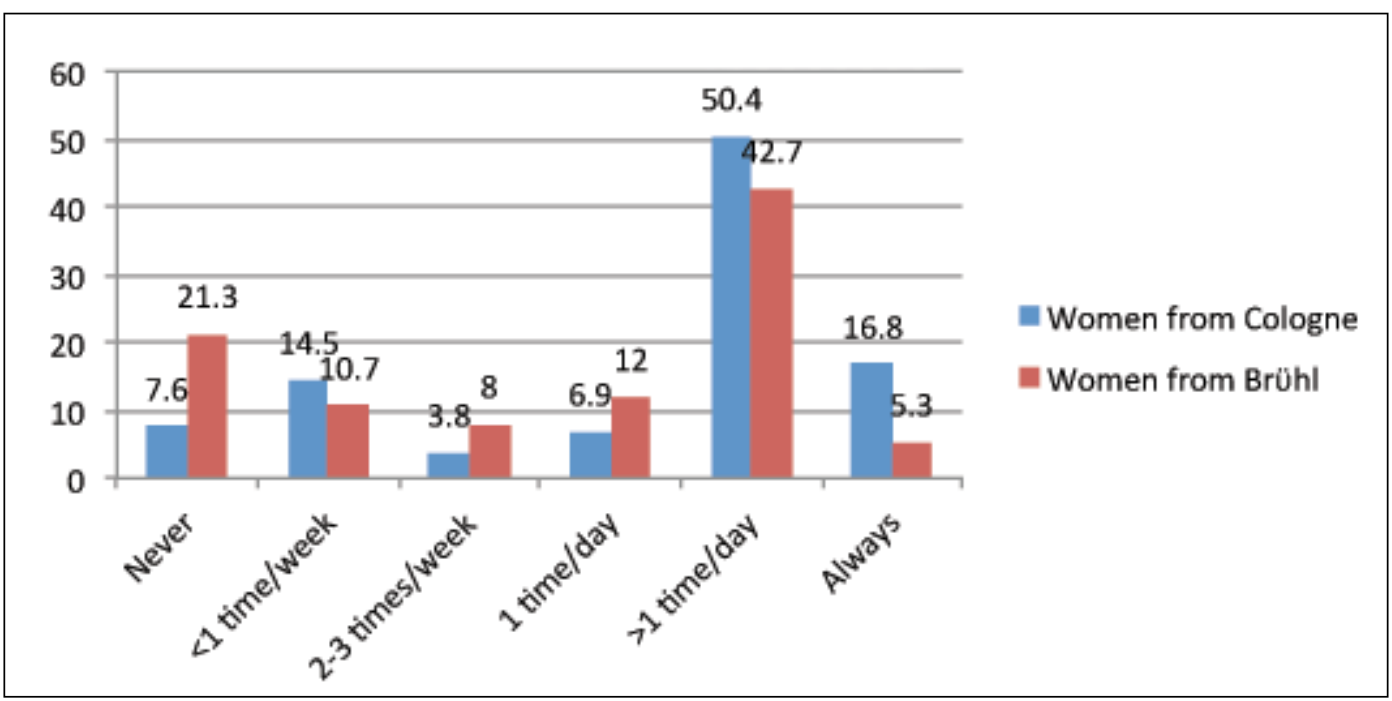

Fig. 3. "How often do you lose urine?" Number in percentage. Mann-Whitney U test: $p=0.002$.

could indicate that the negative impact of urinary incontinence on everyday life was perceived as significantly lower by patients from Brühl. The results suggest that women from rural areas perceive a lesser extent of impairment resulting from their urinary incontinence than women from large cities.

Therefore, an urban-rural gradient with regard to the subjective psychological strain on patients suffering from urinary incontinence can be described. The following statements could reveal possible causes for this observation: "I no longer dare to leave my house" or "I have to adjust my fluid intake to my plans for the day." These statements suggest a connection with leisure activity. After collecting data from 11521 patients, Irwin and colleagues described the negative impact of urinary incontinence on daily activities outside the home. In this study, $36.4 \%$ of women suffering from an overactive bladder $(\mathrm{OAB})$ and urine loss stated that they were worried about activities outside of the home. ${ }^{8}$ It can be presumed that life in the city is more active, so that urinary incontinence has a greater impact on daily life than in rural areas. Therefore, it is more difficult for city women to deal with with urinary incontinence and to develop coping strategies. Conversely, this could explain why patients from rural regions had lower ICIQ-SF scores and frequently stated they did not desire treatment. Another hypothesis is that coping strategies commonly used by people suffering from urinary incontinence, such as fluid intake reduction, prophylactic urination or even the avoidance of social or physical activity, 3,9 are enough for rural women; these coping strategies still allow them to engage in their leisure activities. This provides a possible explanation for the lower psychological strain on women who live in rural areas.

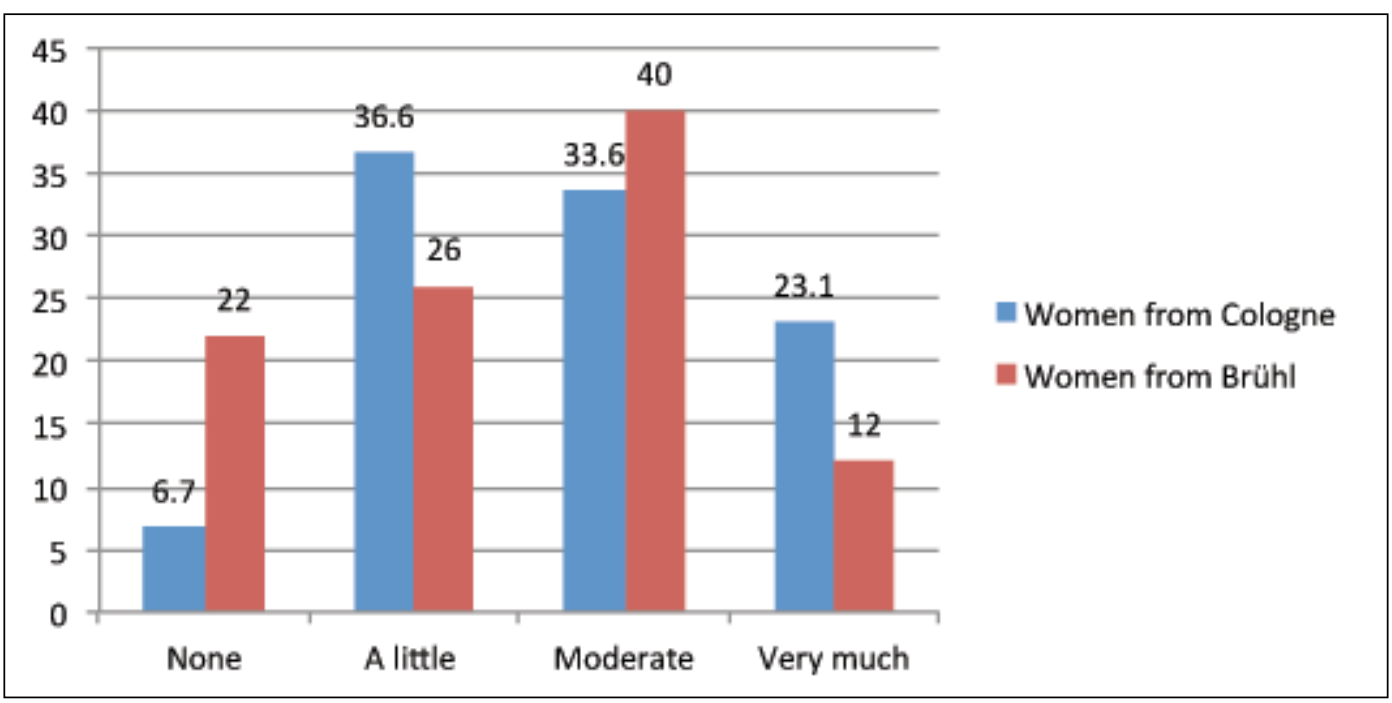

Fig. 4. "How much urine do you lose on average?" Number in percentage. Mann-Whitney U test: $p=0.037$. 
Wille et al.

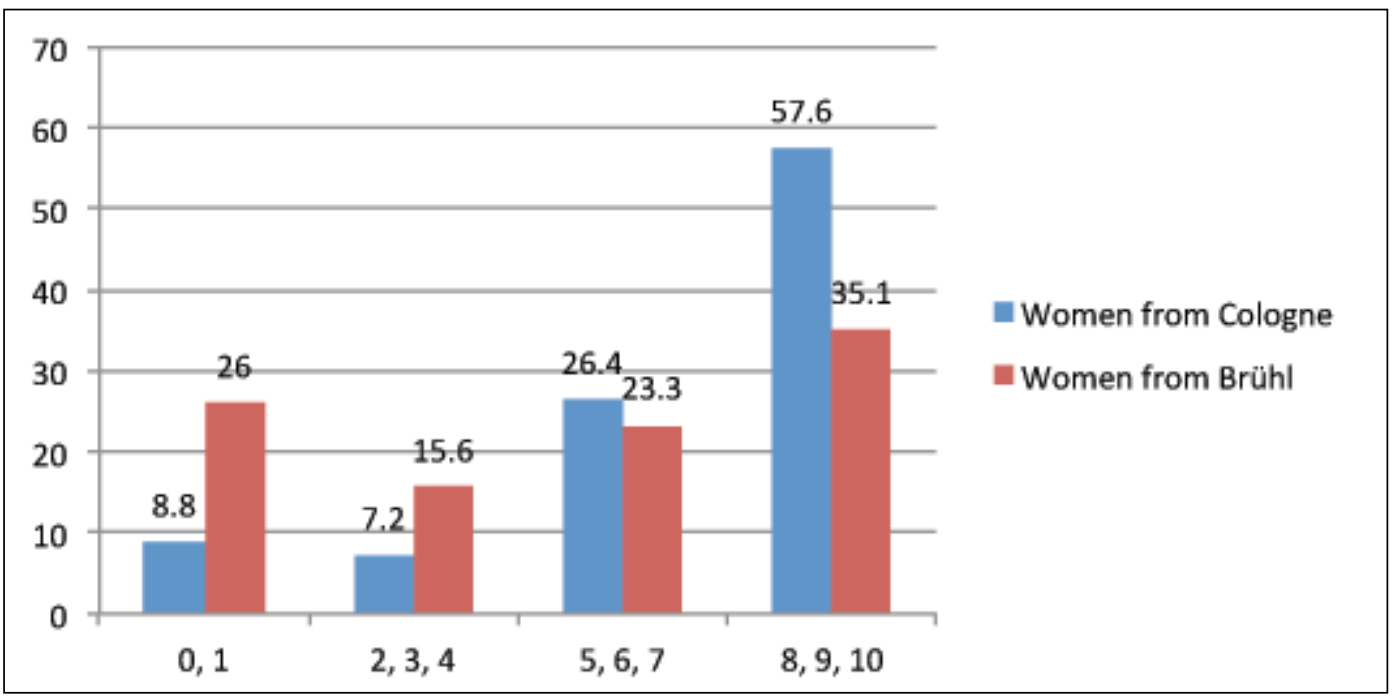

Fig. 5. "How much does the loss of urine affect your daily life?" Number in percentage. Mann-Whitney U test: $p<0.001$.

In this assessment, the severity of urinary incontinence was determined with the number of pads used per day. It is well-known that this method is only an approximate measure for the severity of incontinence. Patients change their pads at varying degrees of wetness. Therefore, it cannot be established whether women in Cologne may be more aware of their personal hygiene and change their pads at a lower levels of wetness than women from Brühl. Furthermore, there can be great variation between self-reported daily use of pads and measured volume of urine loss. Therefore, the number of pads used per day cannot be viewed as directly correlating with the severity of urinary incontinence. ${ }^{10} \mathrm{~A}$ greater disease-specific psychological strain (ICIQ-SF) could possibly lead to an increased physical sensitivity and, therefore, also to an increased use of pads, as was the case in city women. The use of a pad test would be more exact. ${ }^{11}$ The severity of urinary incontinence is crucial as it strongly correlates with quality of life. ${ }^{3,12,13}$

Despite the different response pattern in both populations, the ICIQ correlated well with the severity of urinary incontinence (Fig. 6). With only 4 questions, the questionnaire impresses with its simplicity. Franco and colleagues emphasize the good correlation between the pad test and the ICIQ compared with other commonly used questionnaires, such

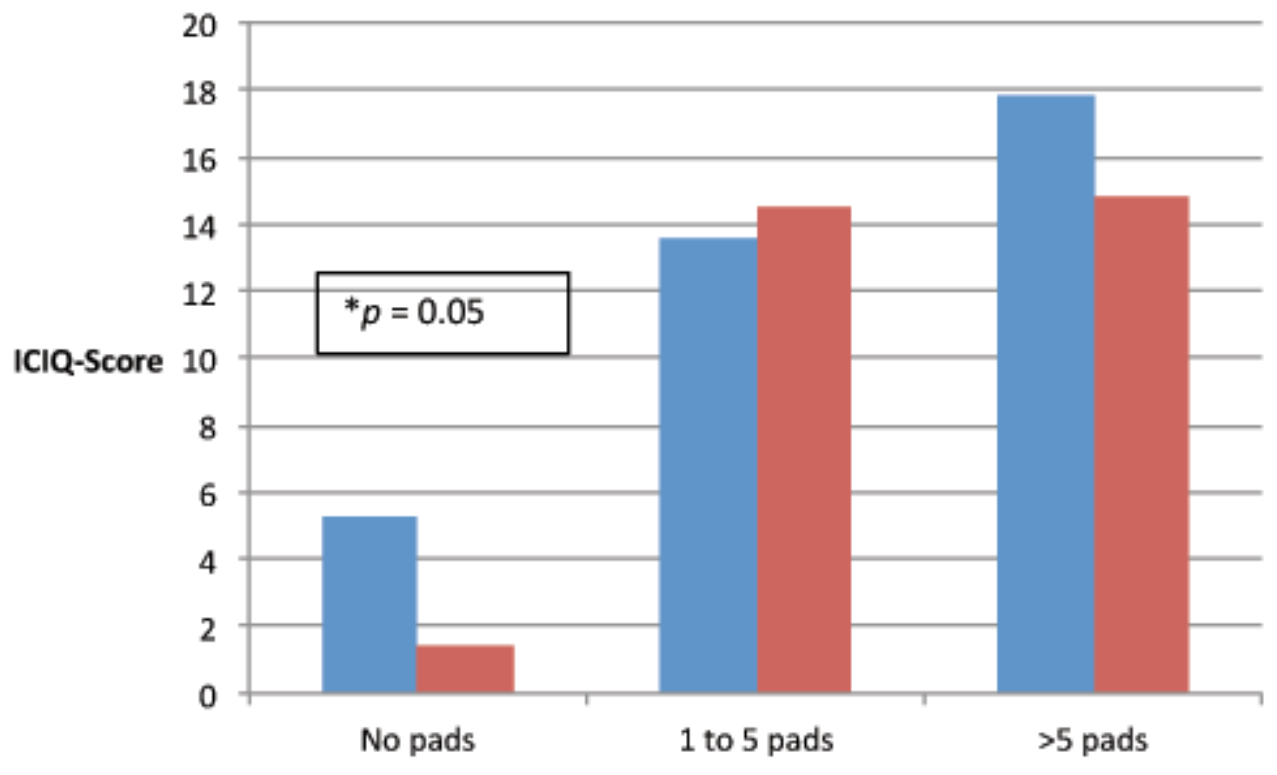

Women from Cologne

Women from Brühl

Fig. 6. Correlation between ICIO-SF score and number of pads used per day. ICIQ: International Consultation on Incontinence Questionnaire-Short Form; ${ }^{*}$ significant difference. 
as the Urogenital Distress Inventory (UDI-6), Incontinence Impact Questionnaire (IIQ-7), the Stamey grading scale, or a visual analogue scale (VAS). ${ }^{14,15}$ The questions on the ICIQ-SF are simply worded and are easily understood by everyone. Due to the manageable extent of the "catalogue of questions," almost all of the questionnaires were filled out correctly and were therefore used in our analysis. Only 3 of the questionnaires from Cologne and 4 from Brühl group were not filled out completely.

Another thesis regarding the different response patterns is that the education and awareness about therapeutic options for urinary incontinence vary between the two populations. ${ }^{3,16}$ One could assume that women in Cologne were more informed, whereas patients living in rural areas might have regarded urinary incontinence as a controllable symptom associated with advancing age.

The retrospective study design and the absence of sociodemographic data are limitations of this study. The use of a pad test could provide further information. Because of the small group size, a subgroup analysis with respect to the individual assessment of patients with stress incontinence, urge incontinence, and mixed incontinence did not have considerable statistical significance. A further limitation is the analyzed sample size and the related moderate statistical power. Nevertheless, the sensitivity analysis could determine differences in ICIQ-SF and the number of pads used per day between the groups with a high statistical power of $95 \%$ and a probability of making a Type I error of 5\% (type I errors: 0.05 and type II errors: 0.05). The comparative analysis of $\mathrm{OAB}$ wet and $\mathrm{OAB}$ dry patients would be of great interest in the future.

\section{Conclusion}

Finally, after extensive research, it must be emphasized that this study is the first one to conduct a social area analysis of urinary incontinence. The existence of an urban-rural gradient with regard to urinary incontinence and the diseasespecific psychological strain on women was demonstrated for the first time. This should serve as a motivation to conduct further prospective studies with a bigger sample size. These studies should not only focus on somatic factors, but should also collect sociodemographic data (marital status, job, social status, daily activities, as well as questionnaires for the assessment of the psychological profile) to be able to understand the patient and her desire for treatment in a holistic context.

Acknowledgements: Sebastian Wille was supported by the German Federal Ministry of Research and Education (BMBF grant 01KN1106). The project was supported by the Center for Clinical Trial Cologne (ZKS Köln) medical department and the German Federal Ministry of Research and Education (BMBF grant 01KN1106).
Competing interests: Dr. Wille, Dr. Katarzyna, Dr. Ahrens, Dr. Eminaga and Dr. Engelmann all declare no competing financial or personal interests.

This paper has been peer-reviewed.

\section{References}

1. Irwin DE, Kopp ZS, Agatep B, et al. Worldwide prevalence estimates of lower urinary tract symptoms, overactive bladder, urinary incontinence and bladder outlet obstruction. BJU Int 2011;108:1132-8. http://dx.doi.org/10.1111/j.1464-410X.2010.09993.x

2. Beutel $M E$, Hessel $A$, Schwarz $R$, et al. Prevalence of urinary incontinence in the German population [in German]. Urologe A 2005;44:232-8. hitp://dx.doi.org/10.1007/s00120-005-0791-y

3. Papanicolaou $S$, Hunskaar $S$, Lose $G$, et al. Assessment of bothersomeness and impact on quality of life of urinary incontinence in women in France, Germany, Spain and the UK. BJU Int 2005;96:831-8. http:// dx.doi.org/10.1111/i.1464-410X.2005.05722.x

4. Berglund AL, Eisemann M, Lalos $A$, et al. Predictive factors of the outcome of primary surgical treatment of stress incontinence in women. Scand J Urol Nephrol 1997;31:49-55. http://dx.doi. org/10.3109/00365599709070302

5. Thuroff JW, Abrams P, Andersson KE, et al. EAU Guidelines on urinary incontinence. Eur Urol 201 1;59:387400. http://dx.doi.org/10.1016/i.eururo.2010.11.021. Epub 2010 Nov 24.

6. Abrams $\mathrm{P}$, Cardozo L, Fall M, et al. The standardisation of terminology in lower urinary tract function: Report from the standardisation sub-committee of the International Continence Society. Urology 2003;61:37-49. http://dx.doi.org/10.1016/S0090-4295(02)02243-4

7. Coyne K, Kelleher C. Patient reported outcomes: The ICIQ and the state of the art. Neurourol Urodyn 2010;29:645-51. http://dx.doi.org/10.1002/nau.20911

8. Irwin DE, Milsom I, Kopp Z, et al. Impact of overactive bladder symptoms on employment, social interactions and emotional well-being in six European countries. BJU Int 2006;97:96-100. http://dx.doi. org/10.1111/i.1464-410X.2005.05889.x

9. Diokno AC, Burgio K, Fultz NH, et al. Medical and self-care practices reported by women with urinary incontinence. Am J Manag Care 2004;10:69-78.

10. Dylewski DA, Jamison MG, Borawski KM, et al. A statistical comparison of pad numbers versus pad weights in the quantification of urinary incontinence. Neurourol Urodyn 2007;26:3-7. http://dx.doi. org/10.1002/nau.20352

11. Richmond DH, Sutherst JR, Brown MC. Quantification of urine loss by weighing perineal pads. Observation on the exercise regimen. Br J Urol 1987;59:224-7. http://dx.doi.org/10.1111/i.1464-410X.1987. tb04610.x

12. Monz B, Chartier-Kastler E, Hampel C, et al. Patient characteristics associated with quality of life in European women seeking treatment for urinary incontinence: Results from PURE. Eur Urol 2007;51:1073-81. http://dx.doi.org/10.1016/j.eururo.2006.09.022

13. Chiaffarino $F$, Parazzini $F$, Lavezzari $M$, et al. Impact of urinary incontinence and overactive bladder on quality of life. Eur Urol 2003;43:535-8. http://dx.doi.org/10.1016/S0302-2838(03)00097-6

14. Franco AV, Lee F, Fynes MM. Is there an alternative to pad tests? Correlation of subjective variables of severity of urinary loss to the 1 -h pad test in women with stress urinary incontinence. BJU Int 2008;102:586-90. http://dx.doi.org/10.1111/i.1464-410X.2008.07612.x

15. Assessment and treatment of urinary incontinence. Scientific Committee of the First International Consultation on Incontinence. Lancet 2000;355:2153-8. http://dx.doi.org/10.1016/S01406736(00)02389-8

16. O'Donnell $M$, Lose $G$, Sykes $D$, et al. Help-seeking behaviour and associated factors among women with urinary incontinence in France, Germany, Spain and the United Kingdom. Eur Urol 2005;47:385-92. http://dx.doi.org/10.1016/j.eururo.2004.09.014

Correspondence: Dr. Sebastian Wille, Department of Urology, University Hospital of Cologne, Kerpener Straßße, Cologne, Germany; sebastian.wille@uk-koeln.de 